Case Report

\title{
Cryptogenic Cirrhosis and Hepatopulmonary Syndrome in a Boy with Hepatic Hemangioma in Botswana: A Case Report and Review of the Literature
}

\author{
Francis Msume Banda $\left(\mathbb{D},{ }^{1}\right.$ Jeremy S. Slone $\left(\mathbb{D},{ }^{2}\right.$ Alan Anderson $\left(\mathbb{D},{ }^{2}\right.$ Marisa Beretta, ${ }^{3}$ \\ Priya Walabh, ${ }^{3}$ Jerome Loveland $\mathbb{C}^{4},{ }^{4}$ Simon Nayler, ${ }^{5}$ and Farirai Fani Takawira ${ }^{6}$ \\ ${ }^{1}$ Department of Paediatrics and Adolescent Health, Faculty of Medicine, University of Botswana, Gaborone, Botswana \\ ${ }^{2}$ Baylor College of Medicine, Texas Children's Cancer and Hematology Centers, Houston, TX, USA \\ ${ }^{3}$ Paediatric Liver Transplant Unit, Wits University Donald Gordon Medical Centre, Charlotte Maxeke Johannesburg Academic \\ Hospital, Johannesburg, South Africa \\ ${ }^{4}$ Department of Paediatric Surgery, School of Clinical Medicine, University of Witwatersrand, Johannesburg, South Africa \\ ${ }^{5}$ Wits University Donald Gordon Medical Centre, Drs Gritzman \& Thatcher Inc., Johannesburg, South Africa \\ ${ }^{6}$ Department of Paediatrics, Steve Biko Academic Hospital, University of Pretoria, Pretoria, South Africa
}

Correspondence should be addressed to Francis Msume Banda; fmbanda@yahoo.co.uk

Received 24 June 2017; Revised 9 October 2017; Accepted 31 October 2017; Published 19 December 2017

Academic Editor: Roland Broadbent

Copyright (C) 2017 Francis Msume Banda et al. This is an open access article distributed under the Creative Commons Attribution License, which permits unrestricted use, distribution, and reproduction in any medium, provided the original work is properly cited.

Hepatic hemangiomas are considered to be the most common benign tumors of the liver. They are often found incidentally while investigating for other causes of liver disease. Hemangiomas that are less than $10 \mathrm{~cm}$ are not expected to cause any problems. Typically, they do not enlarge and, apart from regular follow-up, no definitive treatment is indicated. This is a posthumous case report of a male child with a medium-sized hemangioma from infancy, complicated by cryptogenic cirrhosis and hepatopulmonary syndrome. It demonstrates the challenges of managing a child with such complicated conditions in a resource-limited setting.

\section{Case Report}

An 8-month-old boy was admitted to the Paediatric Ward of Princess Marina Hospital (PMH), the main government referral hospital in Botswana, with abdominal distention and nonbile-stained, nonprojectile vomiting for 2 weeks. No fever, irritability, diarrhoea, or poor feeding was reported. The child was born at term by uncomplicated spontaneous vaginal delivery to a mother who was already on highly active antiretroviral therapy (HAART) before pregnancy. His birth weight was $2950 \mathrm{~g}$. The patient was enrolled into the Perinatal Mother-to-Child Transmission programme as per Botswana guidelines [1]. His neonatal period was uneventful, and his HIV-DNA polymerase chain reaction was negative at 18 months of age.

The child was previously admitted to $\mathrm{PMH}$ when he was 3 months old with culture-negative sepsis and received empiric intravenous antibiotics. On examination during an admission at the age of 8 months, he was slightly lethargic with dry mucus membranes and a capillary refill time of less than 2 seconds. The anterior fontanelle was slightly sunken. Oxygen saturation in room air was 99\%. Vital signs and anthropometric measurements were within normal limits. There was no respiratory distress or dysmorphic features. In addition, the patient had mild scleral icterus. The abdomen was distended and soft; however, an irregular and nontender hepatomegaly of $6 \mathrm{~cm}$ was palpable below the right subcostal margin, with no splenomegaly. The rest of the physical examination was unremarkable.

Full blood count showed mild leukocytosis and normocytic anemia, whilst liver function tests demonstrated a mild transaminitis. Renal function tests showed raised creatinine and urea consistent with dehydration. Serum electrolytes and thyroid function tests were normal. 
TABLE 1: Laboratory results.

\begin{tabular}{|c|c|c|}
\hline Age & $8 \mathrm{~m}$ & $4 y$ \\
\hline \multicolumn{3}{|l|}{$\mathrm{FBC}^{\mathrm{a}}$} \\
\hline WBC $\left(5-10 \times 10^{3} / \mathrm{mL}\right)$ & 12 & 8 \\
\hline Neutrophils (40-60\%) & 68 & 42 \\
\hline Lymphocytes (20-40\%) & 31 & 28 \\
\hline $\mathrm{Hb}(11.5-14 \mathrm{~g} / \mathrm{dL})$ & 10 & 17.1 \\
\hline $\operatorname{MCV}(75-90 \mathrm{fL})$ & 88 & 67.5 \\
\hline Platelets $\left(145-450 \times 10^{3} / \mathrm{mL}\right)$ & 470 & 100 \\
\hline \multicolumn{3}{|l|}{$\mathrm{LFTs}^{\mathrm{b}}$} \\
\hline Total bilirubin $(<17.1 \mu \mathrm{mol} / \mathrm{L})$ & 0.8 & 0.53 \\
\hline Total protein $(63-80 \mathrm{mg} / \mathrm{dL})$ & 76.3 & 71.7 \\
\hline Albumin $35-55 \mathrm{mg} / \mathrm{dL}$ & 34.5 & 33 \\
\hline ALP (50-160 IU/L) & 257.8 & 262 \\
\hline $\operatorname{ALT}(0-30 \mathrm{IU} / \mathrm{L})$ & 78 & 75.4 \\
\hline AST (0-40 IU/L) & 86.3 & 84 \\
\hline GGT (0-30 IU/L) & 63.6 & 69 \\
\hline LDH (140-280 IU/L) & 220 & 262 \\
\hline \multicolumn{3}{|l|}{$\mathrm{U}$ and $\mathrm{E}^{\mathrm{c}}$} \\
\hline $\mathrm{Na}(135-145 \mathrm{mmol} / \mathrm{L})$ & 142 & - \\
\hline $\mathrm{K}(3.5-5.5 \mathrm{mmol} / \mathrm{L})$ & 3.8 & - \\
\hline $\mathrm{Cl}(98-106 \mathrm{mmol} / \mathrm{L})$ & 101 & - \\
\hline Urea $(7-14 \mathrm{mmol} / \mathrm{L})$ & 22 & - \\
\hline Creatinine $(88-176 \mu \mathrm{mol} / \mathrm{L})$ & 83.7 & - \\
\hline \multicolumn{3}{|l|}{$\operatorname{TFTs}^{\mathrm{d}}$} \\
\hline FT4 $(3.5-6.5 \mu \mathrm{g} / \mathrm{dL})$ & 3.78 & - \\
\hline T3 (11.5-22.7 ng/dL) & 20.13 & - \\
\hline TSH $(0.35-5.5 \mu \mathrm{U} / \mathrm{mL})$ & 4.81 & - \\
\hline \multicolumn{3}{|l|}{ Coagulation } \\
\hline aPTT $(30-45 \mathrm{~s})$ & 35 & 30.6 \\
\hline INR $(0.8-1.2)$ & 0.97 & 1.13 \\
\hline \multicolumn{3}{|l|}{ Serum serology studies } \\
\hline Hepatitis $A$ and $B$ viruses & Negative & Negative \\
\hline \multicolumn{3}{|l|}{ Autoimmune screen } \\
\hline ANAs & - & Negative \\
\hline Serum immunoglobulins & - & Normal \\
\hline
\end{tabular}

${ }^{\mathrm{a}}$ Full blood count; ${ }^{\mathrm{b}}$ liver function tests; ${ }^{\mathrm{c}}$ urea and electrolytes; ${ }^{\mathrm{d}}$ thyroid function tests.

Hepatitis virus serology was negative (Table 1). Urine and blood cultures were negative after 5 days of incubation. Chest $\mathrm{X}$-ray was unremarkable.

Abdominal ultrasound showed hepatomegaly $(5 \mathrm{~cm} \times 5 \mathrm{~cm} \times 5 \mathrm{~cm})$ with mild ascites. The spleen, gallbladder, pancreas, kidneys, aorta, and inferior vena cava were normal. There was no retroperitoneal lymphadenopathy. Magnetic resonance imaging scan of the abdomen 3 months later showed mild hepatomegaly with a large well-encapsulated exophytic lesion $(5 \mathrm{~cm} \times 5 \mathrm{~cm} \times 5.3 \mathrm{~cm})$ in the left lobe of the liver consistent with hemangioma. He was started on propranolol therapy to treat the hemangioma. Between the age of 1 and 4 years, he had several abdominal ultrasound scans, and all showed that the liver mass remained the same size.

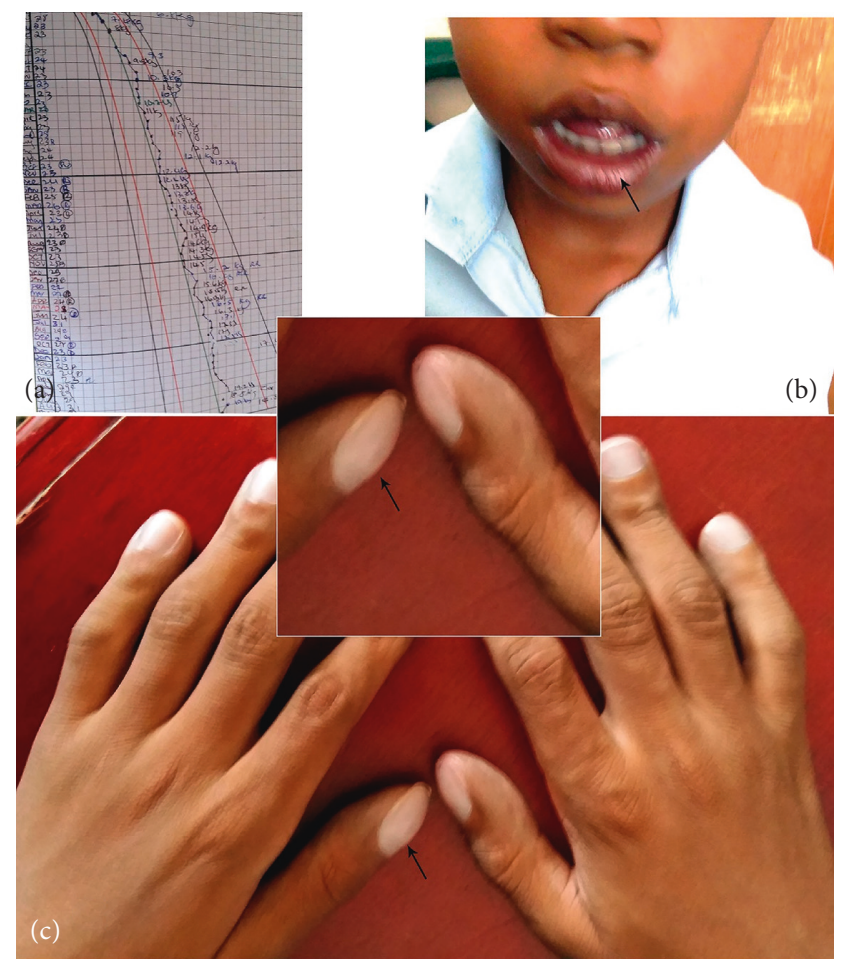

Figure 1: (a) Weight-for-age plot for the patient. Growth consistently above $0 \mathrm{Z}$-score (middle line on the image) throughout the under-five period. (b) Central cyanosis (arrow). (c) Finger clubbing (arrows).

At the age of 4 years, he was growing well, with weight plotting consistently above $0 \mathrm{Z}$-score weight-for-age. Developmental milestones were appropriate for age. However, for the first time, he was noted to be cyanosed, both peripherally and centrally, with oxygen saturation of $70 \%$ in room air, improving to $85 \%$ with supplemental oxygen by nasal prongs. He had developed conjunctival chemosis and finger clubbing (Figure 1). He had no jaundice, pallor, oedema, or lymphadenopathy. In addition, he had a hyperdynamic apex in the 5th intercostal space in the left midclavicular line. The first heart sound was normal, and there was a $2 / 6$ ejection systolic murmur at the tricuspid area that could also be heard over the praecordium. There was no triple rhythm. In addition, the patient had mild subcostal and intercostal recessions, but the lung fields were clear on auscultation. At this point, the abdomen was not distended, but there was hepatosplenomegaly, extending $6 \mathrm{~cm}$ below the subcostal margin. There was no hepatic bruit or ascites.

Of note on the full blood count were polycythemia, microcytosis, and thrombocytopenia, with a hemoglobin of $17.1 \mathrm{~g} / \mathrm{dL}$, mean corpuscular volume of $67.5 \mathrm{fL}$, and platelet count of $100 \times 109 / \mathrm{L}$. Liver function tests showed no significant changes from previous. Coagulation profile was normal (Table 1).

With these examination and laboratory findings, we strongly suspected hepatopulmonary syndrome although he had no overt clinical signs of hepatic cirrhosis. We thought that he had developed portal hypertension, which could explain the splenomegaly and the thrombocytopenia. $\mathrm{He}$ was referred to a hepatobiliary specialist in South Africa, where computed tomographic scan of the abdomen and 


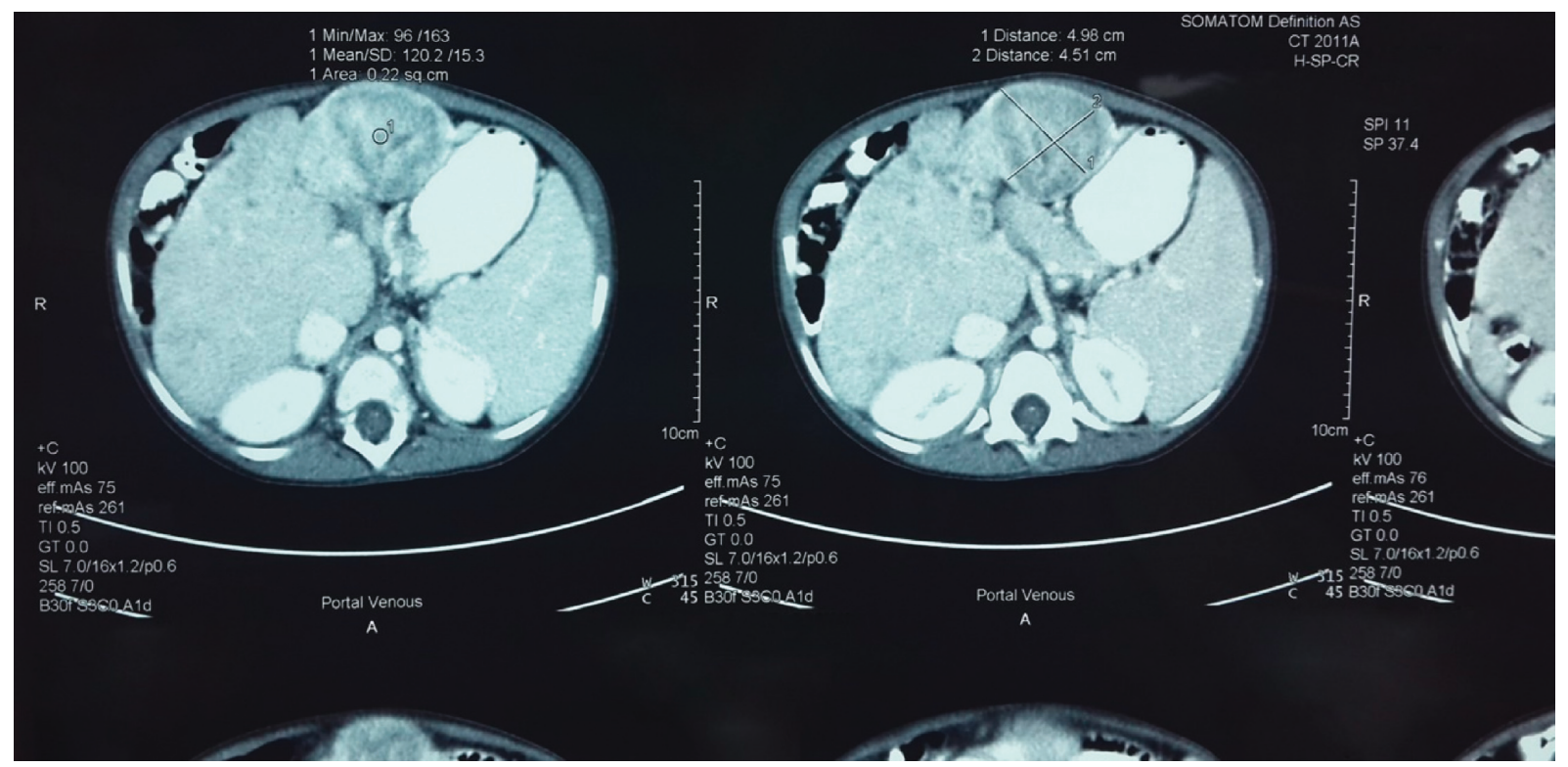

(a)
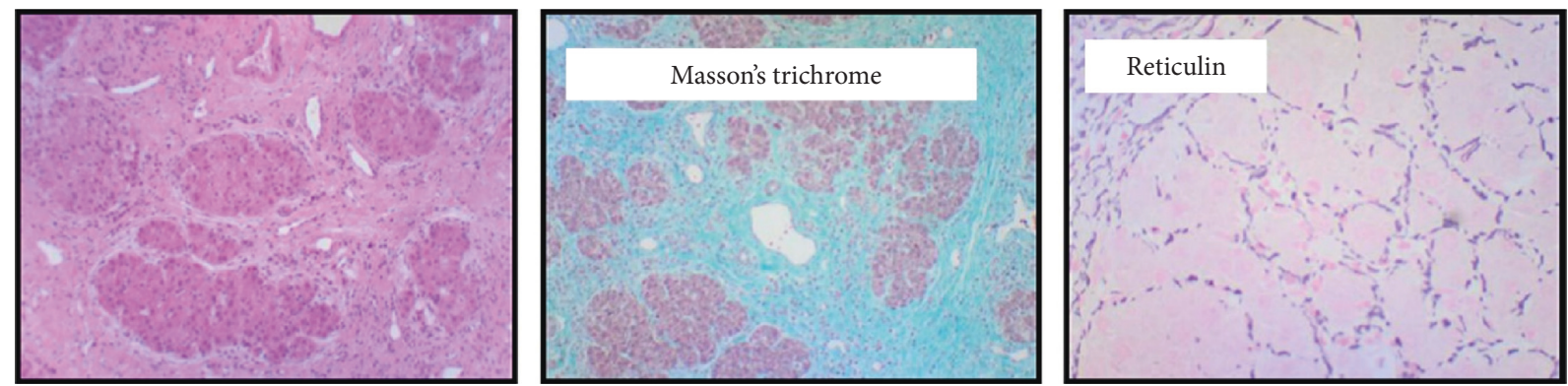

(b)

FIgURE 2: (a) CT scan of the abdomen. Note the hepatic hemangioma (crossed lines 1 and 2). (b) Liver histology. Left to right: Liver parenchyma is present which, although subcapsular, shows evidence of marked distortion of the normal architecture, with fibrosis present surrounding regenerative-type nodules. Masson trichome stain shows extensive interstitial fibrosis surrounding regenerative-type nodules, as can be appreciated on the microphotograph. Reticulin stain shows twinning of the cell plates, which can be appreciated on the microphotograph.

pelvis showed a large mass in segment III of the left lobe of the liver $(4.98 \times 4.51 \mathrm{~cm})$, that was suggestive of hemangioma, and had not changed in size over the years (Figure 2). There was no intrahepatic bile duct dilatation. Gallbladder, pancreas, kidneys, bowel, and mesentery were normal. There was a $10 \mathrm{~cm}$ splenomegaly with no ascites.

Transesophageal echocardiography showed an anatomically normal heart with normal valves, normal chamber size and function, and no intracardiac shunts (patent foramen ovale or septal defects). The internal diameters for the left ventricle were $42.7 \mathrm{~mm}$ (diastolic) and $28.1 \mathrm{~mm}$ (systolic). Ejection fraction was $64 \%$ (normal). Shortening fraction was $34 \%$ (normal). All major vessels were of normal diameter (inferior vena cava: $5.52 \mathrm{~mm}$; right pulmonary artery: $8.32 \mathrm{~mm}$; main pulmonary artery: $15.19 \mathrm{~mm}$; aorta: $22.63 \mathrm{~mm}$ ). There were no features of pulmonary hypertension. Contrast enhancement with saline showed a delayed opacification of the left atrium (positive bubble test), suggesting an intrapulmonary right-toleft shunt most probably due to pulmonary vascular dilatation. The $\mathrm{PaO}_{2}$ was $<34 \mathrm{mmHg}$, and oxygen saturation in room air was $65 \%$ ( $80 \%$ on nasal oxygen).
Exploration with a view to resection of the liver lesion revealed no mass. Instead, advanced cirrhosis was noted.

A wedge liver biopsy showed grossly distorted architecture with regenerative micronodules of hepatocytes surrounded by dense fibrotic septa showing portoportal and portovenous linkage (Figure 2(b)). Mild inflammation was present in the septa, but there was no definitive ductal plate abnormality (bile duct malformation). There were slightly dilated portal venules. The Masson trichrome stain confirmed dense well-established fibrosis in the bridging septa, and the reticulin stain confirmed twinning of the cell plates. There was no evidence of cholestasis and a range of special stains excluded Wilson's disease, alpha-1 antitrypsin disease, and metabolic diseases. No hemangioma was represented on the wedge biopsy.

All other studies, including hepatitis virus serology, autoimmune screen, and copper studies, were also negative. The patient was assessed as having cryptogenic cirrhosis and severe hepatopulmonary syndrome (in view of chronic liver disease, chronic hypoxia, and the delayed opacification saline bubble test). He was assessed in the liver transplant unit 
and was considered to be a candidate for liver transplantation. However, in view of the severity of the hepatopulmonary syndrome, he was put on home oxygen to try and prevent his pulmonary status from deteriorating and improve his arterial oxygen content. He was advised to return 2 months later when he would be worked up for liver transplantation. Sadly, he was unable to return to South Africa for his next appointment due to financial constraints. He was on home oxygen until his demise. An autopsy was offered, but the parents declined to have it done.

\section{Discussion}

Hepatic hemangiomas are considered the most common benign tumors of the liver. They are often found incidentally while investigating for other causes of liver disease. They are classified according to their size into capillary (less than $3 \mathrm{~cm}$ in greatest diameter), medium (between $3 \mathrm{~cm}$ and $10 \mathrm{~cm}$ ), and giant or cavernous (more than $10 \mathrm{~cm}$ ) [2]. Our child had a mediumsized hemangioma, for which, apart from regular follow-up, no active interventions are required [3]. The fact that it neither increased in size nor was it found on laparotomy suggests that it did not play any role in the clinical deterioration of our child and had most likely undergone spontaneous resolution.

Various treatment options for hemangiomas have been described in the literature. These include the use of drugs like corticosteroids, interferon- $\alpha$, and vincristine, as well as surgical excision, laser ablation, embolization, and liver transplantation [4]. We chose propranolol, a $\beta$-adrenergic antagonist, which is an efficacious and safe treatment for hemangiomas $[5,6]$. It is easy to source in our government hospital, so our patient was therefore assured of a constant supply.

Hepatopulmonary syndrome is a well-recognized pulmonary complication of liver cirrhosis. It is usually diagnosed in the presence of a triad of liver disease, oxygenation defect, and intrapulmonary microvascular dilatations [7] on pulmonary angiography. However, contrastenhanced transthoracic echocardiography with saline (bubble test, as done in our patient) is an equally reliable investigation to ascertain the presence of pulmonary vascular dilatation. It is highly sensitive in confirming intrapulmonary vascular dilatations, such that it is regarded as the standard in diagnosing hepatopulmonary syndrome [8]. However, it does not distinguish between saline bubble passage through dilated pulmonary capillaries and arteriovenous malformations. It would have been best to confirm this with pulmonary angiography or technetium-99m MAA nuclear study $[9,10]$, which we were unable to do in our case.

Dyspnea has both positive and negative predictive values of $100 \%$ for hepatopulmonary syndrome. Cyanosis has a negative predictive value of $97 \%$ while finger clubbing has been reported to have a negative predictive value of up to $75 \%$ [11]. Our patient did not have spider angiomas, although they have been widely described as cutaneous markers of the hepatopulmonary syndrome, especially in the setting of intrapulmonary vascular dilatations [11, 12].

Hepatopulmonary syndrome is classified as mild $\left(\mathrm{PaO}_{2} \geq 80 \mathrm{mmHg}\right)$, moderate $\left(\mathrm{PaO}_{2} \geq 60<80 \mathrm{mmHg}\right)$, severe $\left(\mathrm{PaO}_{2} \geq 50<60 \mathrm{mmHg}\right)$ and very severe $\left(\mathrm{PaO}_{2}<50 \mathrm{mmHg}\right)$.
These patients consistently have elevated serum levels of nitric oxide and carboxyhemoglobin, both of which have been postulated to play a role in the pathogenesis of the syndrome [8] and normalize after liver transplantation. The nitric oxide is linked to the causation of the pulmonary vascular dilatation [13] while the carboxyhemoglobin is linked to the severe hypoxemia [14]. However, the defect in oxygenation is largely attributed to increased blood flow through the dilated pulmonary vessels in the alveolar capillary bed. While alveolar ventilation remains constant, the increased blood flow through the low pressure system creates a ventilation-perfusion mismatch [15]. This explains why $\mathrm{PaO}_{2}$ increases when a patient with hepatopulmonary syndrome breathes $100 \%$ oxygen [16].

In infancy, biliary atresia and genetic metabolic disease are the commonest cause of chronic liver disease, while chronic viral hepatitis and autoimmune disease predominate after infancy. Cryptogenic cirrhosis accounts for 5-15\% overall [17]. Cryptogenic cirrhosis and cirrhosis due to hepatitis B virus infection are the commonest causes of hepatopulmonary syndrome in the medical literature [11]. Our patient most likely had cryptogenic cirrhosis based on the physical findings and nonconclusive results of extensive investigations. The patient lived for an additional 2.5 years despite the severe hypoxia.

The patient had two admissions in infancy due to severe illnesses. We did not find their aetiology, and investigations did not point towards immunodeficiency. However, we are also aware that HIV-exposed uninfected infants are at increased risk for severe infections in the first year of life [18].

Liver transplantation is the only successful treatment for hepatopulmonary syndrome [19]. Patients with severe hepatopulmonary syndrome do achieve a resolution of the hypoxemia after liver transplantation [20-22], although such patients often have a very difficult posttransplant existence, characterized by many intensive care admissions, long recovery periods, and oxygen dependence, with a significant risk of mortality $[23,24]$. It is generally accepted that posttransplantation mortality is directly related to the severity of the hypoxemia before the transplantation [23]. A baseline $\mathrm{PaO}_{2} \leq 50 \mathrm{mmHg}$ has been associated with poor prognosis whether transplantation is done or not [25], and is considered the strongest predictor of death [26]. A well-established posttransplant health care system and a conducive socioeconomic environment at home are other important considerations [27]. The current protocol regarding severe hepatopulmonary syndrome and liver transplantation at our referral facility requires that families be extensively counseled regarding the dramatically increased mortality and morbidity rate and extended the choice to progress to transplantation. A child with severe hepatopulmonary syndrome will not be excluded from transplantation unless he/she is excluded by factors that are applicable to all other transplant candidates. The main limiting factors to transplantation in our child were the poor socioeconomic status of the family (parents were unemployed and did not have private medical aid) and the child's inability to return for the 2 months' appointment, which cast considerable doubt on the child's readiness to access the facility after transplantation, as currently there is no paediatric posttransplant health care system in Botswana. 


\section{Conclusion}

Our case report, the first of its kind to be reported from Botswana, demonstrates the difficult challenges of managing a child with cryptogenic cirrhosis and hepatopulmonary syndrome in the setting of liver transplant considerations.

\section{Conflicts of Interest}

The authors declare that there are no conflicts of interest regarding the publication of this paper.

\section{Acknowledgments}

The authors would like to sincerely thank the parents of the child for providing informed consent to publish the case (including the images of the child) in this case report.

\section{References}

[1] Ministry of Health, "Republic of Botswana: handbook of the Botswana 2016 integrated HIV clinical care guidelines," February 2017, http://www.moh.gov.bw/Publications/Handbook_ HIV_treatment_guidelines.pdf.

[2] N. Bajenaru, V. Balaban, F. Săvulescu, I. Campeanu, and T. Patrascu, "Hepatic hemangioma-review," Journal of Medicine and Life, vol. 8, pp. 4-11, 2015.

[3] Y. Nakanuma, "Review: non-neoplastic nodular lesions in the liver," Pathology International, vol. 45, no. 10, pp. 703-714, 1995.

[4] A. Akhavan and J. H. Zippin, "Current treatments for infantile hemangiomas," Journal of Drugs in Dermatology, vol. 9, no. 2, pp. 176-180, 2010.

[5] H. Zaher, H. Rasheed, R. A. Hegazy, R. A. Hegazy, D. M. Abdelhalim, and H. I. Gawdat, "Oral propranolol: an effective, safe treatment for infantile hemangiomas," European Journal of Dermatology, vol. 21, no. 4, pp. 558-563, 2011.

[6] J. Bertrand, R. Sammour, and C. McCuaig, "Propranolol in the treatment of problematic infantile hemangioma: review of 35 consecutive patients from a vascular anomalies clinic," Journal of Cutaneous Medicine and Surgery, vol. 16, no. 5, pp. 317-323, 2012.

[7] V. Ho, "Current concepts in the management of hepatopulmonary syndrome," Vascular Health and Risk Management, vol. 4, no. 5, pp. 1035-1041, 2008.

[8] R. Rodriguez-Roisin and M. J. Krowka, "Hepatopulmonary syndrome-a liver-induced lung vascular disorder," New England Journal of Medicine, vol. 358, no. 22, pp. 2378-2387, 2008.

[9] M. J. Stewart, "Contrast echocardiography," Heart, vol. 89, no. 3, pp. 342-348, 2003.

[10] J. Offer, L. Green, A. R. Houghton, and J. Campbell, “A case of hepatopulmonary syndrome," Echo Research and Practice, vol. 2, no. 2, pp. K25-K27, 2015.

[11] A. H. M. Alizade, S. R. Fatemi, V. Mirzaee et al., "Clinical features of hepatopulmonary syndrome in cirrhotic patients," World Journal of Gastroenterology, vol. 12, no. 12, pp. 19541956, 2006.

[12] A. O. Silverio, D. C. Guimaraes, L. F. Elias, E. O. Milanez, and S. Naves, "Are the spider angiomas skin markers of hepatopulmonary syndrome?," Arquivos de Gastroenterologia, vol. 50, no. 3, pp. 175-179, 2013.

[13] G. Cremora, T. W. Higenbottam, V. Mayoral et al., "Elevated exhaled nitric oxide in patients with hepatopulmonary syndrome," European Respiratory Journal, vol. 8, no. 8, pp. 1883-1885, 1995.

[14] M. R. Arguedas, B. B. Drake, A. Kapoor, and B. Fallon, "Carboxyhemoglobin levels in cirrhotic patients with and without hepatopulmonary syndrome," Gastroenterology, vol. 128, no. 2, pp. 328-333, 2005.

[15] P. Berthelot, J. G. Walker, S. Sherlocks, and L. Reid, "Arterial changes in the lungs in cirrhosis of the liver-lung spider nevi," New England Journal of Medicine, vol. 274, no. 6, pp. 291-298, 1966.

[16] M. J. Krowka, G. A. Wiseman, O. L. Burnett et al., "Hepatopulmonary syndrome: a prospective study of relationships between severity of liver disease, $\mathrm{PaO}_{2}$ response to $100 \%$ oxygen and brain uptake after (99m) Tc MAA lung scanning," Chest, vol. 118, no. 3, pp. 615-624, 2000.

[17] R. B. Pinto, A. C. R. Schneider, and T. R. Da Silveira, "Cirrhosis in children and adolescents: an overview," World Journal of Hepatology, vol. 7, no. 3, pp. 392-405, 2015.

[18] A. Slogrove, B. Reikie, S. Naidoo et al., "HIV-exposed uninfected infants are at increased risk for severe infections in the first year of life," Journal of Tropical Pediatrics, vol. 58, no. 6, pp. 505-508, 2012.

[19] R. Rodriguez-Roisin and M. J. Krowka, "Is severe arterial hypoxaemia due to hepatic disease an indication for liver transplantation? A new therapeutic approach," European Respiratory Journal, vol. 7, no. 5, pp. 839-842, 1994.

[20] L. S. Eriksson, C. Soderman, B. G. Ericzon, L. Eleborg, J. Wahren, and G. Hedenstierna, "Normalization of ventilation perfusion relationships after liver transplantation in decompensated cirrhosis: evidence for a hepatopulmonary syndrome," Hepatology, vol. 12, no. 6, pp. 1350-1357, 1990.

[21] J. J. McCloskey, C. Schleien, K. Schwarz, A. Klein, and P. Colombani, "Severe hypoxemia and intrapulmonary shunting reversed by liver transplantation in a pediatric patient," Journal of Pediatrics, vol. 118, no. 6, pp. 902-904, 1991.

[22] J. M. LaBerge, M. L. Brandt, P. Lebecque et al., "Reversal of cirrhosis-related pulmonary shunting in two children by orthotopic liver transplantation," Transplantation, vol. 53, no. 5, pp. 1135-1138, 1992.

[23] M. J. Krowka, R. H. Wiesner, and J. K. Heimbach, "Pulmonary contraindications, indications and MELD exceptions for liver transplantation: a contemporary view and look forward," Journal of Hepatology, vol. 59, no. 2, pp. 367-374, 2013.

[24] M. J. Krowka, "Hepatopulmonary syndrome: what are we learning from interventional radiology, liver transplantation, and other disorders?," Gastroenterology, vol. 109, no. 3, pp. 1009-1013, 1995.

[25] K. L. Swanson, R. H. Wiesner, and M. J. Krowka, "Natural history of hepatopulmonary syndrome: impact of liver transplantation," Hepatology, vol. 41, no. 5, pp. 1122-1129, 2005.

[26] M. R. Arguedas, G. A. Abrams, M. J. Krowka, and M. P. Fallon, "Postoperative evaluation outcomes and predictors of mortality in patients with hepatopulmonary syndrome undergoing liver transplantation," Hepatology, vol. 37, no. 1, pp. 192-197, 2003.

[27] B. Song, M. Schulze, I. Goldschmidt, R. Haux, U. Baumann, and M. Marschollek, "Home monitoring and decision support for international liver transplant children," Studies in Health Technology and Informatics, vol. 192, pp. 268-272, 2013. 


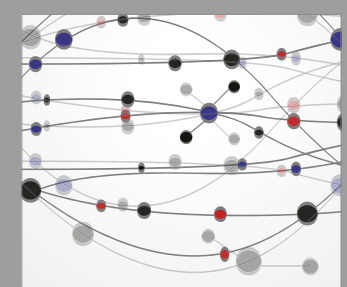

The Scientific World Journal
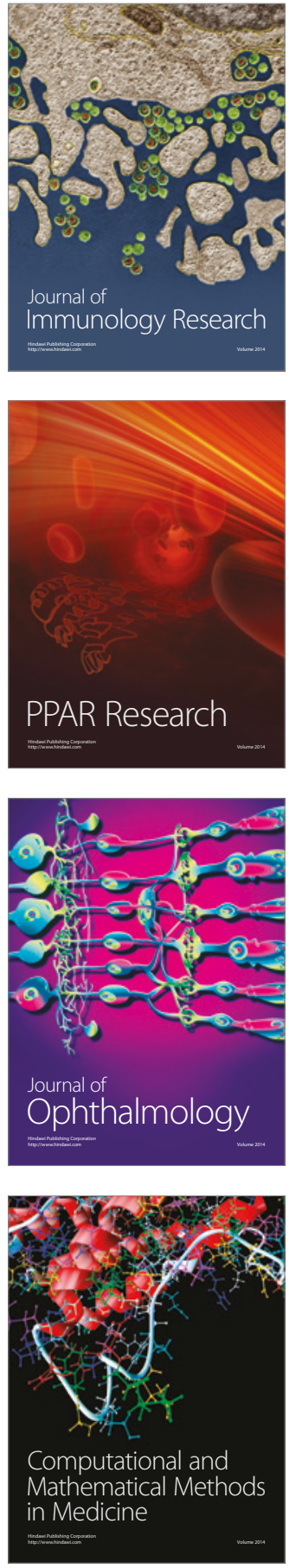

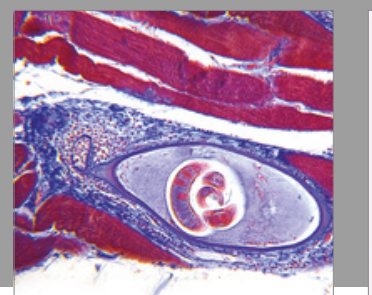

Gastroenterology Research and Practice
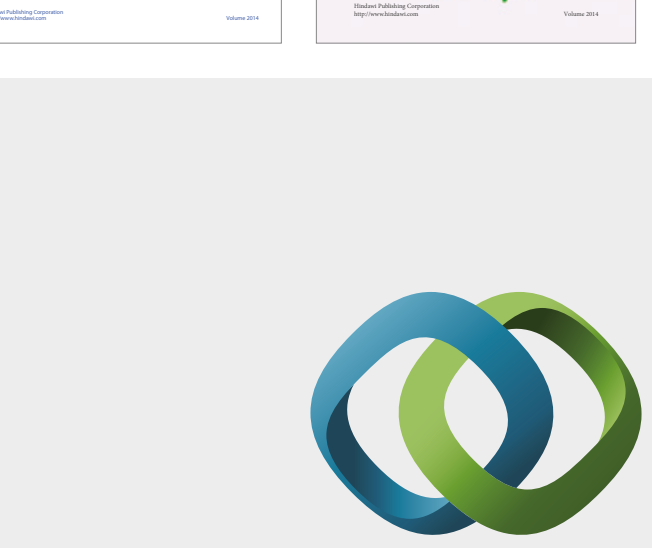

\section{Hindawi}

Submit your manuscripts at

https://www.hindawi.com
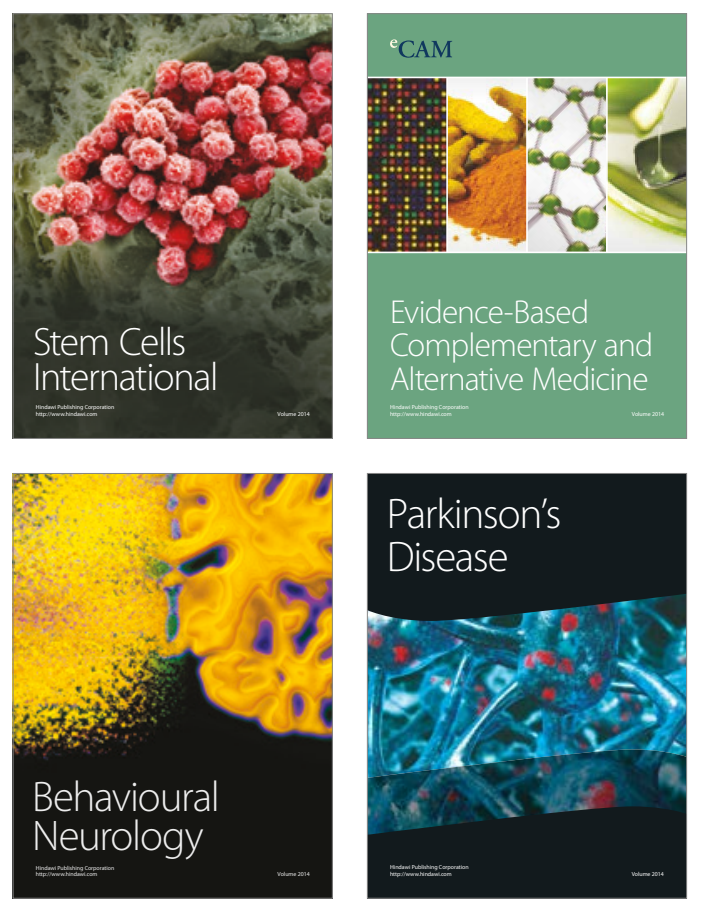
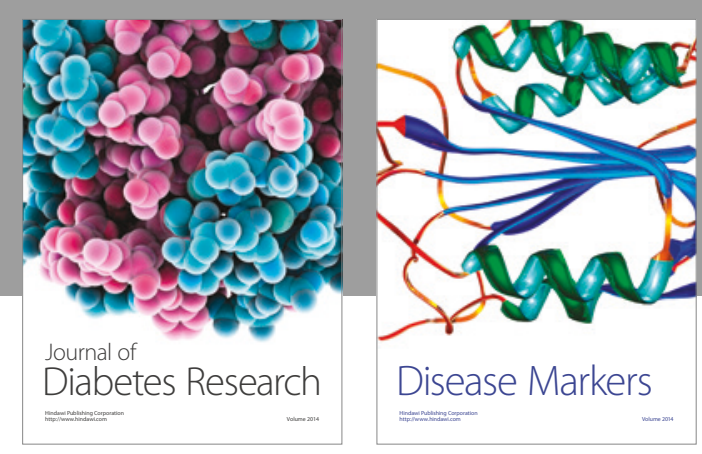

Disease Markers
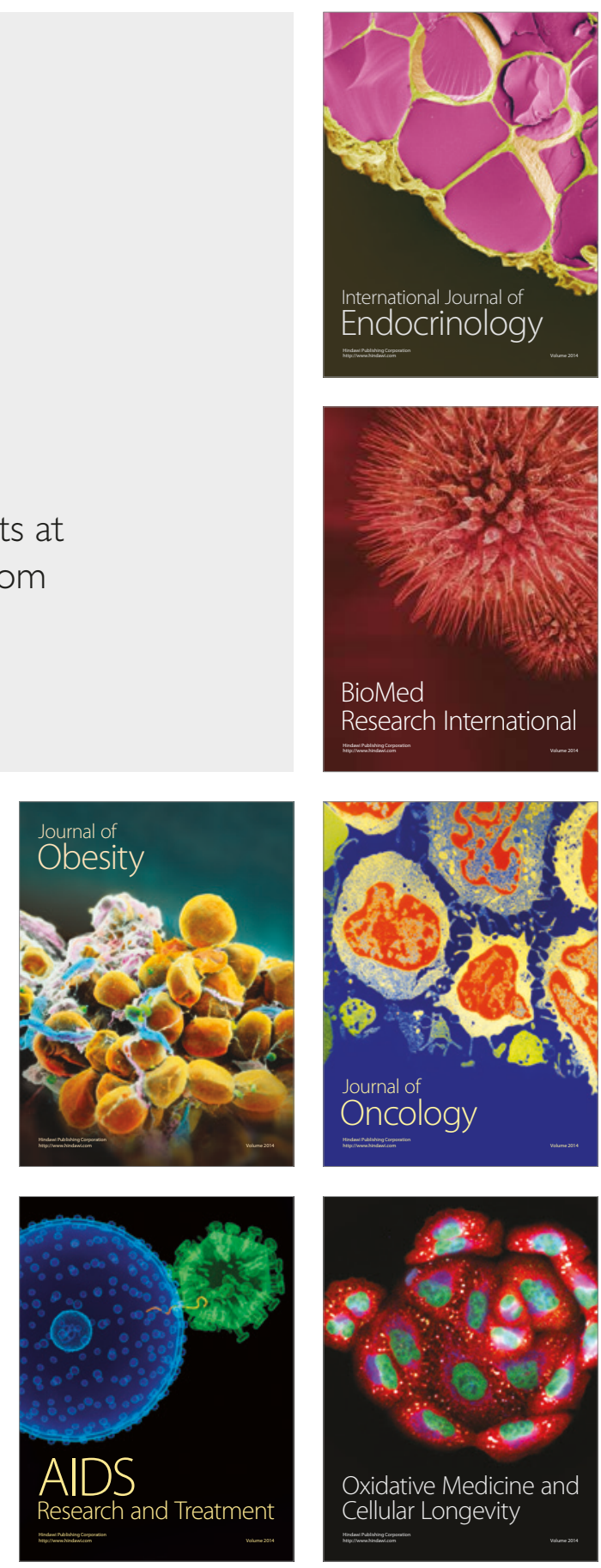